\title{
Factors affecting the cognitive profile of 11-year-old children born very preterm
}

\author{
Anna Nyman ${ }^{1}$, Tapio Korhonen ${ }^{1}$, Petriina Munck ${ }^{1}$, Riitta Parkkola ${ }^{2}$, Liisa Lehtonen ${ }^{3}$ and Leena Haataja ${ }^{4}$ \\ on behalf of the PIPARI Study Group ${ }^{5}$
}

BACKGROUND: Preterm birth is a risk for cognitive development. This study assessed the cognitive profile of children born very preterm at the age of 11 years as well as the associated risk factors.

METHODS: A total of 128 children born very preterm were included. Magnetic resonance imaging was performed at term age. Cognitive development was assessed using the full-scale intelligence quotient (IQ) and four domains of the Wechsler Intelligence Scale for Children, fourth edition (WISC-IV), Finnish translation. The results were compared with test norms.

RESULTS: Most study children performed at average (51\%) or low average (21\%) levels in the full-scale IQ assessment. The correlation between 5 - and 11-year full-scale IQ was 0.73 $(P<0.001)$. Compared with the normative data, children born very preterm performed poorer in all domains of the cognitive profile. The only significant risk factor for poor general cognition was major brain pathology. When considering all four domains of WISC-IV, low paternal education, male gender, and low birth weight $z$ score were also found to be significant risk factors.

CONCLUSIONS: Less than one-third of the children born very preterm performed below the low average cognitive level at 11 years of age. Specific neonatal and sociodemographic risk factors were identified as affecting the cognitive profile.

P rotection of cognitive development is an important goal for the perinatal and neonatal care of infants born preterm. Cognitive impairments affect the academic and sociobehavioral functioning of children born preterm increasingly by age and demands (1-3).

The cognitive outcome of children born preterm is poorer compared with that of controls born full-term (3). It has also been suggested that improved neonatal care during the last decades has not improved the cognitive outcome of children born preterm (4). The severity of cognitive deficits is expected to be greater with increasing immaturity (3). However, a recent meta-analysis suggested that the role of being preterm as a prognostic factor for general cognitive development diminishes as children get older, whereas the role of parental education becomes more prominent (5). Many studies have reported a relationship between neonatal brain injury and general cognitive development (6-9). In addition, gestational age (GA), neonatal diagnoses, and sociodemographic factors have been suggested to affect cognitive development, but these effects have been difficult to show when using long-term general cognitive development as an outcome (5). The cognitive profile assessed with Wechsler Intelligence Scale for Children, fourth edition (WISC-IV) $(10,11)$ includes separate domains for verbal comprehension, perceptual reasoning, working memory, and processing speed. Using separate cognitive domains as an outcome measure instead of full-scale intelligence quotient (IQ) allows assessing the relationship between the risk factors and cognitive development in more detail. Different risk factors may have different effects on the cognitive development. Very little information is available with respect to the cognitive outcomes of children born preterm assessed with cognitive measure with factor structure $(2,12-16)$. To our knowledge, information about neonatal and sociodemographic factors associated with the four cognitive domains is currently lacking.

The aim of this study was to describe the cognitive profile of 11-year-old children born very preterm by assessing specific cognitive domains and evaluating the underlying sociodemographic and neonatal risk factors. Our hypotheses were that mean cognitive performance of the children born very preterm is at the average range but lower than the mean test norms, and that neonatal and sociodemographic risk factors have specific effects on the cognitive profile at middle-school age.

\section{METHODS \\ Subjects}

This study is part of a prospective multidisciplinary follow-up study called PIPARI (Development and Functioning of Very Low Birth weight Infants from Infancy to School Age). All very low birth weight $(\leqslant 1,500 \mathrm{~g})$ infants born at Turku University Hospital between 2001 and 2006 who lived in the catchment area were eligible. From the beginning of 2004, the inclusion criteria were expanded to include all

\footnotetext{
${ }^{1}$ Department of Psychology, University of Turku, Turku, Finland; ${ }^{2}$ Department of Radiology, University of Turku and Turku University Hospital, Turku PET Center, Turku, Finland; ${ }^{3}$ Department of Pediatrics, University of Turku and Turku University Hospital, Turku, Finland; ${ }^{4}$ Department of Pediatric Neurology, Children's hospital, University of Helsinki and Helsinki University Hospital, Helsinki, Finland. Correspondence: Anna Nyman (anna.nyman@utu.fi)

${ }^{5}$ The members of PIPARI Study Group are listed before Reference.

Received 17 August 2016; accepted 1 March 2017; advance online publication 24 May 2017. doi:10.1038/pr.2017.64
} 


\section{Cognitive profile of preterm children 1 Articles}

infants born at a very low GA ( $<32$ weeks), even if the birth weight exceeded $1,500 \mathrm{~g}$. At least one of the parents had to speak either Finnish or Swedish-the two official languages in Finland. Data about the prenatal period, delivery, neonatal morbidities, brain imaging findings, and developmental outcomes were systematically collected as part of the PIPARI study protocol. Children with severe congenital anomalies or a diagnosed genetic syndrome affecting their development were excluded. The current study sample consisted of infants born between 2001 and 2004. The PIPARI study protocol was approved by the Ethics Review Committee of the Hospital District of South-West Finland in December 2000 and again in January 2012. All parents who agreed to participate gave written informed consent at neonatal intensive care unit (NICU) after they had received written and oral information. At 11 years of age, the children also gave their own written informed consent after receiving written information.

\section{Developmental Assessments}

Neurosensory impairment. Neurosensory impairment (NSI) was defined as a child having at least one of the following diagnoses: cerebral palsy, severe hearing impairment, or severe visual impairment. When present, cerebral palsy was defined using the classification proposed by Himmelmann et al. (17). The diagnosis of cerebral palsy was determined by a child neurologist (LH) by 2 years of corrected age after a systematic clinical follow-up. Severe hearing impairment was defined as a hearing loss requiring amplification in at least one ear. Severe visual impairment was defined as a visual acuity $<0.3$ or blindness (18).

Cognitive assessment. Cognitive development of the children born preterm was assessed with WISC-IV, Finnish translation $(10,11)$, during the year when they turned 11. Children were assessed in a testing room at the hospital except $13(10 \%)$ of them who were assessed at school. Further, six $(4,7 \%)$ bilingual children preferring Swedish instead of Finnish were assessed with WISC-IV, Finnish translation, by a native psychologist using instructions and questions in Swedish. Full-scale IQ was used as a measure of general intelligence. Full-scale IQ is a composite score from four index scores that provide information about more specific cognitive domains. The Verbal Comprehension Index measures knowledge of word meanings, verbal reasoning, and verbal knowledge acquired from one's environment. The Perceptual Reasoning Index measures visual-constructional skills and visual reasoning abilities. The Working Memory Index measures the immediate recollection and manipulation of verbal sequences. The Processing Speed Index measures short-term visual memory, attention, and visual-motor coordination.

The full-scale IQ and the four index scores were used as continuous variables. The classification of full-scale IQ and index scores is based on the test manual and SDs from the normative test means (10). The scores were considered as (1) average when the quotient was between 90 and 109 (SD between -0.67 and 0.67 ) or above $109,(2)$ low average when the quotient was between 80 and 89 (SD between -1.33 and -0.68 ), (3) in borderline when the quotient was between 70 and 79 (SD between -2.00 and -1.34 ), and (4) extremely low when the quotient was 69 or less (SD below-2.01). Full-scale IQ and index scores were calculated according to ageappropriate and updated norms (mean \pm SD: $100 \pm 15$ in normative population) from the Finnish standardization of the WISC-IV (11). Severely impaired children, whose scores could not be determined, were assigned scores representing $-4.0 \mathrm{SD}$ in the normative data as in previous studies (2). In our cohort, one child who was unable to finish the processing speed measures because of severe motor disability was assigned a score representing $-4.0 \mathrm{SD}$. Three children scored so low on the individual indices that a full-scale IQ could not be counted. Therefore, their full-scale IQ was assigned as -4.0 SD. The neuropsychologist (AN) assessed all of the children. She was not aware of the children's neonatal data to avoid bias from background information.
As previously reported, full-scale IQ of the children born very preterm was assessed at the age of 5 years (19) using WPPSI$\mathrm{R}$, Finnish translation (20). Of the 128 children included in the present study, 120 were successfully assessed also at the age of 5 years. Five of the 5 -year assessments were performed in Swedish using the same translation protocol as in the 11-year assessments.

\section{Risk Factors}

Neonatal variables. GA, growth restriction, and male gender $(21-23)$ at birth were included because of their known role as risk factors for cognitive development. We also included necrotizing enterocolitis (NEC) and brain magnetic resonance imaging (MRI) pathologies at term age, as they were shown significant for 2-year cognition in our cohort (24).

The brain MRI was performed at term age with an open 0.23-T Outlook GP (Philips Medical, Vantaa, Finland) for very preterm infants born between 2001 and April 2004 and with a 1.5-T Philips Intera (Philips Medical Systems, Best, The Netherlands) for very preterm infants born thereafter. The MRI findings were categorized into three groups as follows: (i) normal findings consisted of normal brain anatomy (cortex, basal ganglia and thalami, posterior limb of internal capsule, white matter, germinal matrix, corpus callosum, and posterior fossa structures), width of extracerebral space of $<5 \mathrm{~mm}$, ventricular/brain ratio of $<0.35$, and no ventriculitis; (ii) minor pathologies consisting of consequences from intraventricular hemorrhages (grades 1 and 2), caudothalamic cysts, a width of the extracerebral space of $5 \mathrm{~mm}$, and a ventricular/brain ratio of 0.35 ; and (iii) major pathologies consisting of consequences from intraventricular hemorrhages (grades 3 and 4), an injury in the cortex, basal ganglia, thalamus, internal capsule, corpus callosum, cerebellum, or white matter, as well as increased width of extracerebral space by $>5 \mathrm{~mm}$, a ventricular/brain ratio of $>0.35$, ventriculitis, or other major brain pathologies (infarctions) $(18,25)$. These three categories are used to evaluate the relationship between brain pathology and cognitive outcome.

Psychosocial variables. We included maternal and paternal education as separate variables because of their increasing role by increasing age (5). Official classification of education levels in Finland was used to categorize the parents' education levels as follows: basic education, 9 years ( $\leqslant 9$ years); upper secondary education, 3 more years (over 9-12 years); and higher education, 5 or more years after basic education ( $>12$ years).

\section{Data Analysis}

Drop-out analyses were performed using a $\chi^{2}$-test or Fisher's exact test, as appropriate. In addition, associations between categorical and ordinal variables were studied using $\chi^{2}$-tests for trends. One-sample $t$-test was used to compare the cognitive scores of all children born very preterm, children born extremely preterm, children born very preterm without NSI, and separately boys and girls born very preterm to a mean level of 100 for the normal population. These results are presented with means, SDs, $t$ values, and $P$ values. Twosample $t$-test was used to compare the cognitive scores between boys and girls born preterm. Correlation between full-scale IQ at the age of 5 and 11 years was calculated using Spearman correlation. Bivariate analyses were performed using regression analysis, and the results are presented with adjusted $R^{2}\left(\omega^{2}\right)$ and $P$ values. Multiple regression analysis was used to study the association between cognitive scores and background characteristics. Included in the independent variables of these analyses were maternal education, paternal education, gender, GA, birth weight $z$ score, operated NEC, and findings in the brain MRI. These analyses were repeated, excluding children with NSI. The results of full regression models are presented with adjusted $R^{2}\left(\omega^{2}\right)$, and the results of individual predictor variables are summarized using adjusted $R^{2}$ change $\left(\Delta \omega^{2}\right)$ as an effect size. Statistical analyses were carried out using a 9.4 


\section{Articles $\mid N_{y m a n}$ e tal.}

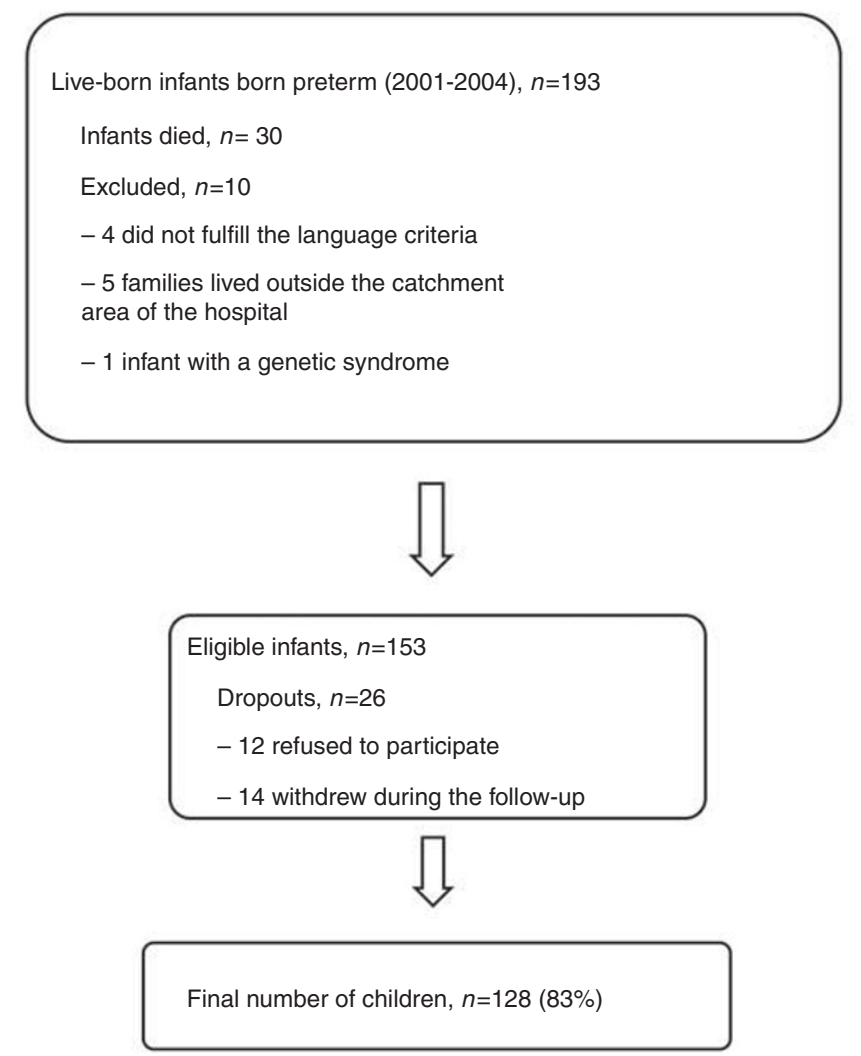

Figure 1. A flow chart outlining how study subjects were selected.

version of SAS Institute Inc. (Cary, NC, USA) for Windows, and $P$ values of $<0.05$ were considered to be statistically significant.

\section{RESULTS}

\section{Subjects}

The flow chart of the participants and the dropouts is presented in Figure 1. The mean age of the children born very preterm at the time of cognitive assessment was 11 years and 1 month (ranging from 10 years and 8 months to 11 years and 7 months). The neonatal characteristics of the very preterm cohort (birth weight $<1,500$ g or GA $<32$ weeks) are shown in Table 1. Ten (7.8\%) of the children born preterm had NSIseight had cerebral palsy and two had hearing impairments. None of the children had severe visual impairments. For comparison, we also report cognitive profile results for extremely preterm children (birth weight $<1,000 \mathrm{~g}$ or GA $<28$ weeks) comprising half of the total group of very preterm children (64/128). Infant characteristics and parental education were compared between the study infants and dropouts. The follow-up rate was $83 \%$ for the very preterm group. The dropouts $(n=26,17 \%)$ had a lower maternal education level $(<12$ years in $65 \%$ of the dropouts, $37 \%$ of the study infants, $P=0.004)$ and were in treatment for retinopathy of prematurity more often than the study infants (in $12 \%$ of the dropouts, $2 \%$ of the study infants, $P=0.034)$. The dropouts were also more often singletons (92\% of the dropouts, $66 \%$ of study infants, $P=0.007$ ).

\section{Cognitive Profile}

Most of the 11-year-old children born very preterm performed at the average range (at the average 51\%, at the low average 21\%) in the assessment of full-scale IQ. Cognitive impairment was defined as borderline for $18 \%$ and as extremely low for $10 \%$ of the children born very preterm. Excluding children with NSI had a nonsignificant effect, as $52 \%$ of the children without NSI performed at the average level and 23\% performed at the low average level. Of the children born extremely preterm, $47 \%$ performed at the average level and $20 \%$ at the low average level in the assessment of full-scale IQ. Cognitive impairment was defined as borderline for $20 \%$ and as extremely low for $13 \%$ of the children born extremely preterm. Full-scale IQs and the four index scores are presented in Table 2. Working memory $(P<0.025$, $t$ value: 2.28 , mean difference: $6.89(95 \% \mathrm{CI}$ $0.9-12.9))$ and processing speed $(P<0.002, t$ value: 3.06 , mean difference: 9.40 (95\% CI 3.3-15.5)) domains were significantly lower in boys born very preterm compared with the girls born very preterm. Mean (SD) full-scale IQ of the present study cohort at the age of 5 years $(n=120)$ was 98.9 (17.7). Correlation between full-scale IQ at the age of 5 and 11 


\section{Cognitive profile of preterm children Articles}

Table 1. Characteristics of the children born very preterm

\begin{tabular}{|c|c|}
\hline Characteristics & $\begin{array}{l}\text { Children born very } \\
\text { preterm }(n=128)\end{array}$ \\
\hline Antenatal corticosteroids, $n$ (\%) & $123(96.0)$ \\
\hline $\begin{array}{l}\text { Gestational age (weeks), mean (SD) [min, } \\
\text { max] }\end{array}$ & $28.8(2.7)[23.0,35.9]$ \\
\hline Birth weight $(g)$, mean (SD) [min, max] & $1080(291.8)[400.0,2025]$ \\
\hline Birth weight $z$ score, mean (SD) & $-1.4(1.6)$ \\
\hline Small for gestational age ${ }^{a}, n(\%)$ & $49(38.3)$ \\
\hline$<28$ weeks $/ \geqslant 28$ weeks & $47 / 81$ \\
\hline$<32$ weeks $/ \geqslant 32$ weeks & $112 / 16$ \\
\hline$\leqslant 1,500 \mathrm{~g} />1,500 \mathrm{~g}$ & $123 / 5$ \\
\hline Male, $n(\%)$ & $68(53.1)$ \\
\hline Apgar $<6$ at $5 \mathrm{~min}^{\mathrm{b}}, n(\%)$ & $30(23.8)$ \\
\hline Multiple birth, $n$ (\%) & $44(34.4)$ \\
\hline Postnatal corticosteroids, $n$ (\%) & $20(15.6)$ \\
\hline Days on ventilator ${ }^{c}$ mean (SD) $[\min , \max ]$ & $8.9(12.5)[0,51.0]$ \\
\hline Days in hospital ${ }^{\mathrm{b}}$ mean (SD) [min, max] & $58.6(30.7)[3,182]$ \\
\hline Treated retinopathy of prematurity, $n(\%)$ & $2(1.6)$ \\
\hline Operated necrotizing enterocolitis, $n(\%)$ & $6(4.7)$ \\
\hline Sepsis or meningitis, $n$ (\%) & $29(22.7)$ \\
\hline Ductal ligation, $n(\%)$ & $17(13.3)$ \\
\hline Chronic lung disease ${ }^{\mathrm{d}}, n(\%)$ & $18(14.1)$ \\
\hline \multicolumn{2}{|l|}{$\mathrm{MRI}^{\mathrm{b}}, n(\%)$} \\
\hline Normal & $70(55.5)$ \\
\hline Minor & $22(17.5)$ \\
\hline Major & $34(27.0)$ \\
\hline \multicolumn{2}{|l|}{ Maternal education ${ }^{\mathrm{b}}, n(\%)$} \\
\hline$\leqslant 9$ years & $12(9.5)$ \\
\hline Over $9-12$ years & $35(27.8)$ \\
\hline$>12$ years & $79(62.7)$ \\
\hline \multicolumn{2}{|l|}{ Paternal education ${ }^{\mathrm{b}}, n(\%)$} \\
\hline$\leqslant 9$ years & $13(10.3)$ \\
\hline Over 9-12 years & $73(57.9)$ \\
\hline$>12$ years & $40(31.7)$ \\
\hline
\end{tabular}

MRI, magnetic resonance imaging.

aDefined as a birth weight of $<-2.0$ SD according to the age- and genderspecific Finnish growth charts.

${ }^{b}$ Missing, $n=2$.

'Missing, $n=1$.

${ }^{\mathrm{d} D e f i n e d}$ as a need for supplementary oxygen at the corrected age of 36 gestational weeks.

years (Figure 2) was statistically significant $(r=0.73$, $P<0.001)$.

\section{Risk Factors and Cognitive Profile}

The covariates were chosen a priori based on clinical judgment and previous literature. Overall regression models for full-scale IQ $\left(P<0.001, \omega^{2}=0.28\right)$, verbal comprehension $\left(P<0.001, \quad \omega^{2}=0.20\right)$, perceptual reasoning $(P<0.001$, $\left.\omega^{2}=0.17\right)$, working memory $\left(P<0.001, \omega^{2}=0.26\right)$, and processing speed $\left(P<0.001, \omega^{2}=0.18\right)$ were performed using the neonatal (GA weeks, birth weight $z$ score, male gender, NEC, and brain MRI findings) and psychosocial (maternal and paternal education) risk factors. Results of the bivariate analysis are reported in the Supplementary Table S1 online.

According to the regression models, major brain pathologies in MRI at term age associated with lower full-scale IQ $\left(P<0.001, \Delta \omega^{2}=0.117\right)$ and with all the IQ domains that is, lower verbal comprehension $\left(P=0.033, \Delta \omega^{2}=0.033\right)$, lower perceptual reasoning $\left(P<0.001, \Delta \omega^{2}=0.133\right)$, lower working memory $\left(P<0.001, \Delta \omega^{2}=0.101\right)$, and lower processing speed $\left(P=0.026, \Delta \omega^{2}=0.037\right)$ at the age of 11 years. Lower paternal education was associated with lower verbal comprehension $\left(P=0.006, \Delta \omega^{2}=0.056\right)$. Male gender was associated with lower working memory $\left(P=0.048, \Delta \omega^{2}=0.018\right)$ and lower processing speed $\left(P=0.003, \Delta \omega^{2}=0.057\right)$. Birth weight $z$ score was associated only with processing speed $(P=0.018$, $\left.\Delta \omega^{2}=0.032\right)$. The Figure 3 represents the results of the regression analyses. Having a major brain MRI pathology was clinically the most important risk factor for the weaker cognitive performance associated with full-scale IQ (a 15-point deficit) and with all four domains (an 8-point deficit on verbal comprehension, a 14-point deficit on perceptual reasoning, a 13-point deficit on working memory, and a 9-point deficit on processing speed). The clinically important impact of lower paternal education on lower verbal comprehension became also evident (a 15-point deficit). After excluding the children with NSI from the analyses $(P<0.001$, $\left.\omega^{2}=0.28\right)$, major pathologies in brain MRI $(P=0.005$, $\left.\Delta \omega^{2}=0.058\right)$ decreased the estimated mean full-scale IQ 11 points, but was no longer significantly associated with verbal comprehension and processing speed.

\section{DISCUSSION}

The general cognitive performance of the children born very preterm was at the average range, but significantly lower than the mean test norms as we expected in our hypothesis. Seventy-two percent of the children born very preterm in this regional cohort performed at the average range. Twenty-eight percent performed below the average range (full-scale IQ below 80 ) compared with $9 \%$ in the general norm population (10). In summary, the whole IQ distribution of the preterm population was shifted to the left compared with the normative values resulting in an 11-point difference in the mean. Further, we wanted to explore whether neonatal and sociodemographic risk factors have specific effects on the cognitive profile at middle school age. The only significant risk factor for poor general cognition was major brain MRI pathology at term age. When considering all four domains of WISC-IV, low paternal education, male gender, and birth weight $z$ score were also found to be significant risk factors for different aspects of cognition. GA was not a significant risk 


\section{Articles | Nyman et al.}

Table 2. Wechsler Intelligence Scale for Children, fourth edition (WISC-IV), scores for all children born very preterm, boys and girls born very preterm, children born very preterm without neurosensory impairment (NSI), and children born extremely preterm

\begin{tabular}{|c|c|c|c|c|c|c|c|c|c|c|}
\hline & $\begin{array}{c}\text { Full-scale } \\
\text { IQ }\end{array}$ & & $\begin{array}{c}\text { Verbal } \\
\text { comprehension }\end{array}$ & & $\begin{array}{l}\text { Perceptual } \\
\text { reasoning }\end{array}$ & & $\begin{array}{l}\text { Working } \\
\text { memory }\end{array}$ & & $\begin{array}{l}\text { Processing } \\
\text { speed }\end{array}$ & \\
\hline & Mean (SD) & $t$ value $^{\mathrm{a}}$ & Mean (SD) & $t$ value $^{\mathrm{a}}$ & Mean (SD) & $t$ value $^{\mathrm{a}}$ & Mean (SD) & $t$ value $^{\mathrm{a}}$ & Mean (SD) & $t$ value $^{\mathrm{a}}$ \\
\hline $\begin{array}{l}\text { All children born } \\
\text { very preterm } \\
(n=128)\end{array}$ & $87.6(18.0)$ & $-7.77^{* * *}$ & $89.8(15.4)$ & $-7.45^{* * *}$ & $91.2(17.7)$ & $-5.64^{* * *}$ & $92.6(17.4)$ & $-4.80^{* * *}$ & $92.9(17.9)$ & $-4.47^{* * *}$ \\
\hline $\begin{array}{l}\text { Boys born very } \\
\text { preterm } \\
(n=68 / 128)\end{array}$ & $85.1(18.0)$ & $-6.81^{* * *}$ & 89.6 (15.9) & $-5.40^{* * *}$ & $90.6(18.9)$ & $-4.10^{* * *}$ & $89.4(16.3)$ & $-5.36^{* * * *}$ & $88.5(17.0)$ & $-5.57^{* * *}$ \\
\hline $\begin{array}{l}\text { Girls born very } \\
\text { preterm } \\
(n=60 / 128)\end{array}$ & 90.5 (17.7) & $-4.16^{* * *}$ & $90.1(15.0)$ & $-5.11^{* * *}$ & $91.8(16.3)$ & $-3.87^{* * *}$ & 96.3 (17.9) & -1.60 & $97.9(17.7)$ & -0.90 \\
\hline $\begin{array}{l}\text { Children born } \\
\text { very preterm } \\
\text { without NSI } \\
(n=118 / 128)\end{array}$ & $89.1(16.8)$ & $-7.05^{* * *}$ & 90.6 (14.9) & $-6.87^{* * *}$ & $92.9(16.2)$ & $-4.77^{* * *}$ & $93.5(17.0)$ & $-4.17^{* * *}$ & $93.9(17.0)$ & $-3.90^{* * *}$ \\
\hline $\begin{array}{l}\text { Extremely } \\
\text { preterm children } \\
(n=64 / 128)\end{array}$ & $85.1(19.4)$ & $-6.13^{* * *}$ & $87.6(16.1)$ & $-6.19 * * *$ & 89.9 (19.5) & $-4.15^{* * *}$ & $90.5(18.0)$ & $-4.24^{* * *}$ & 90.5 (17.7) & $-4.30^{* * *}$ \\
\hline
\end{tabular}

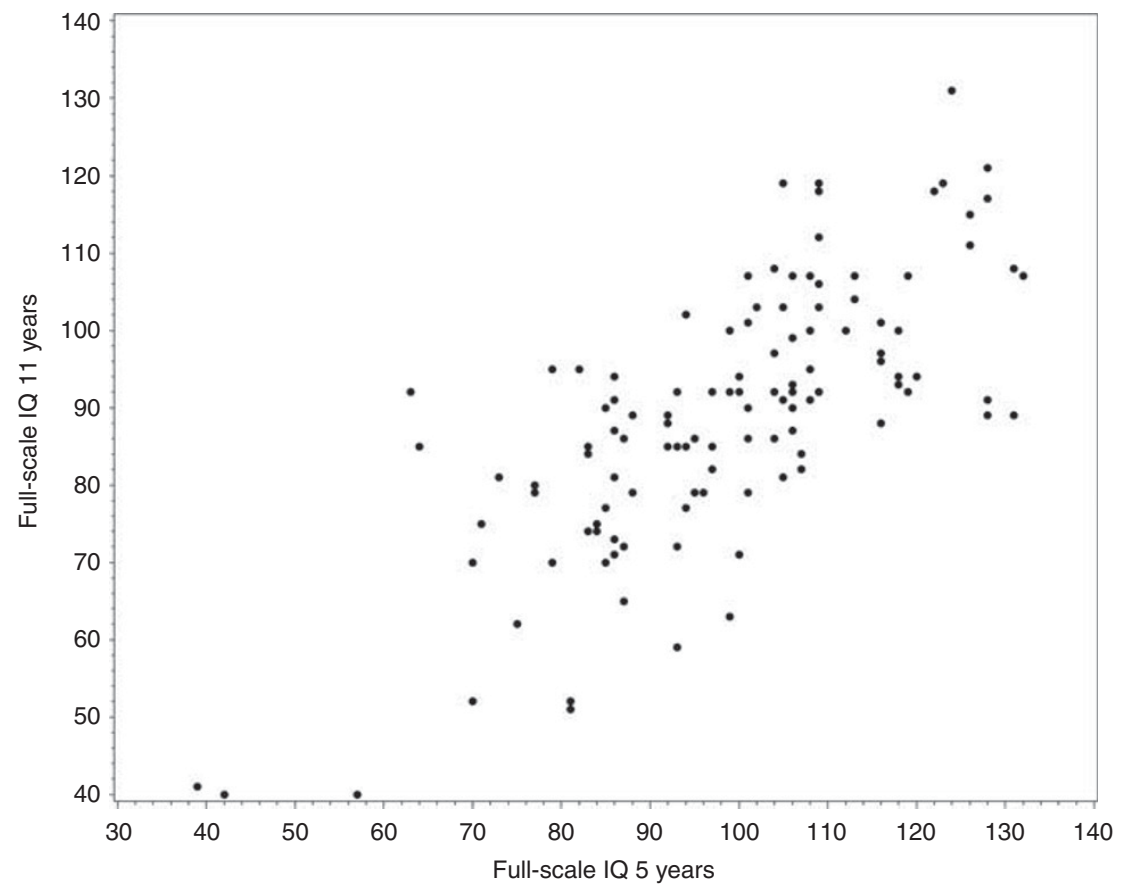

Figure 2. Scatterplot showing the relationship between 5- and 11-year full-scale IQ.

factor for general cognition or four domains of WISC-IV $(10,11)$.

When comparing the cognitive outcomes of children born preterm, it is important to note the inclusion criteria; whether the study reported the outcome for entire population of children born very preterm (i.e., children born below 32 gestational weeks) or only for children born extremely preterm (i.e., children born below 28 gestational weeks) as the youngest infants are usually expected to have long-term effects more commonly $(4,26,27)$. Previously, the WISC-IV $(10,11)$ has been used in several studies, but only few have reported the cognitive profile $(2,12-16)$. To our knowledge, this is the first study reporting cognitive WISC-IV profile for middle-school age children born preterm in 2000s. An Australian study $(2,28)$ also included impaired children when reporting the cognitive profile of 8 -year-old children born 


\section{Cognitive profile of preterm children Articles}

a

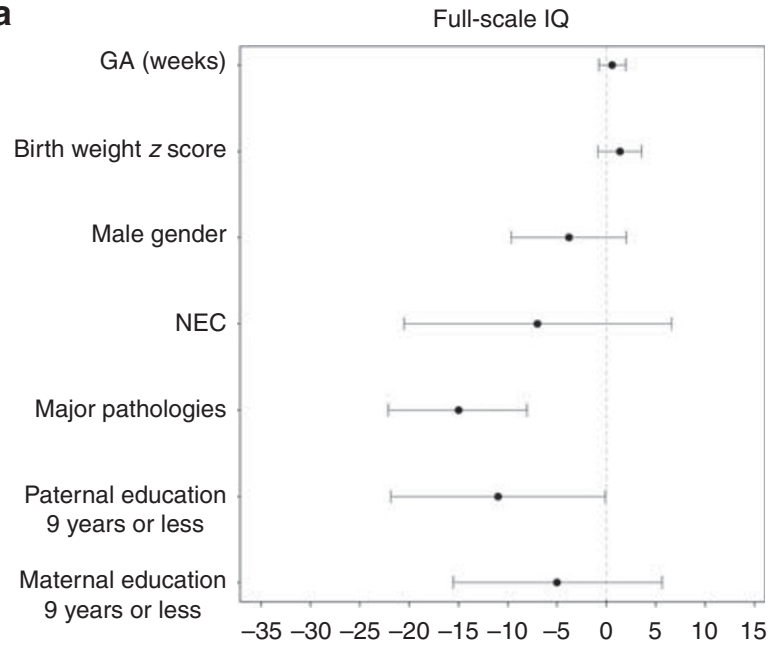

C

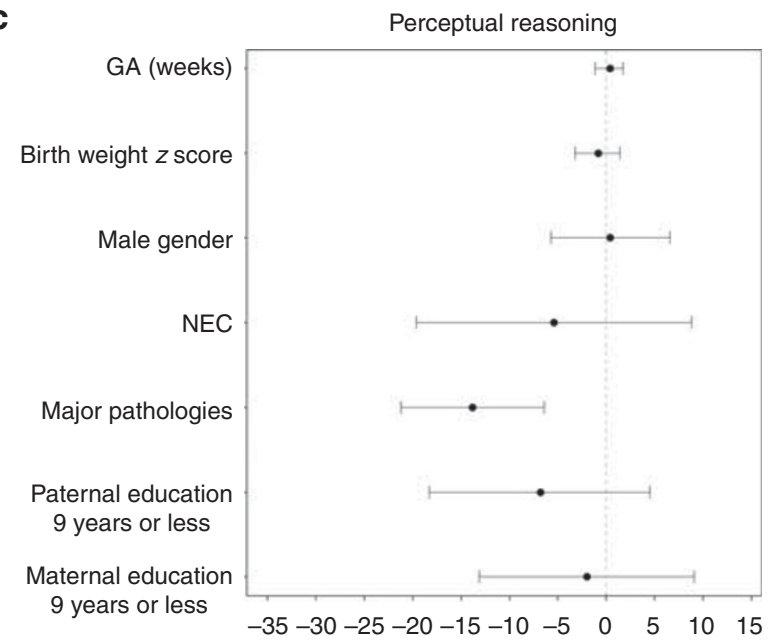

e

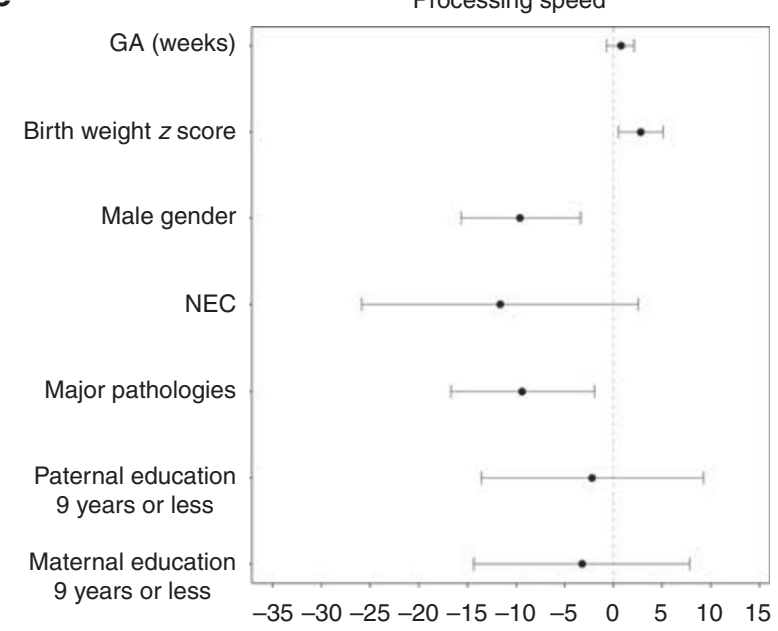

b

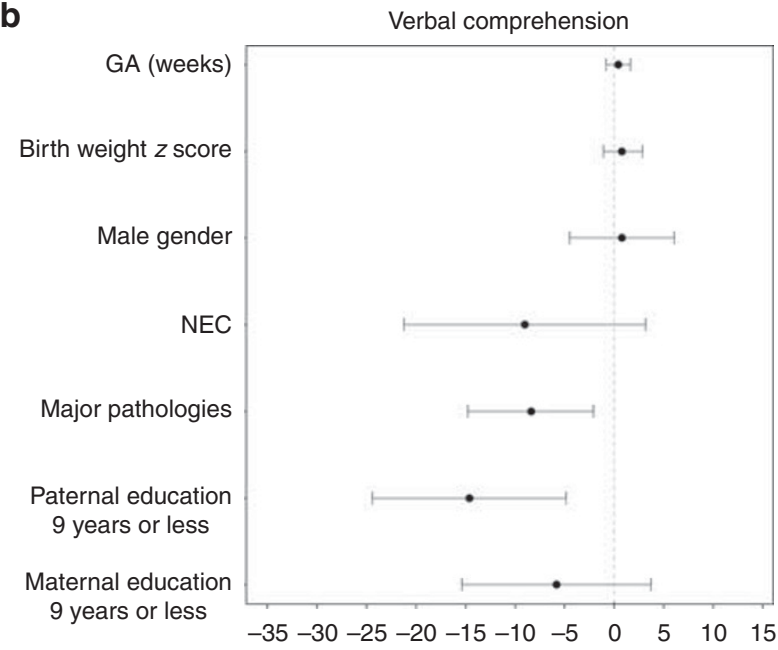

d

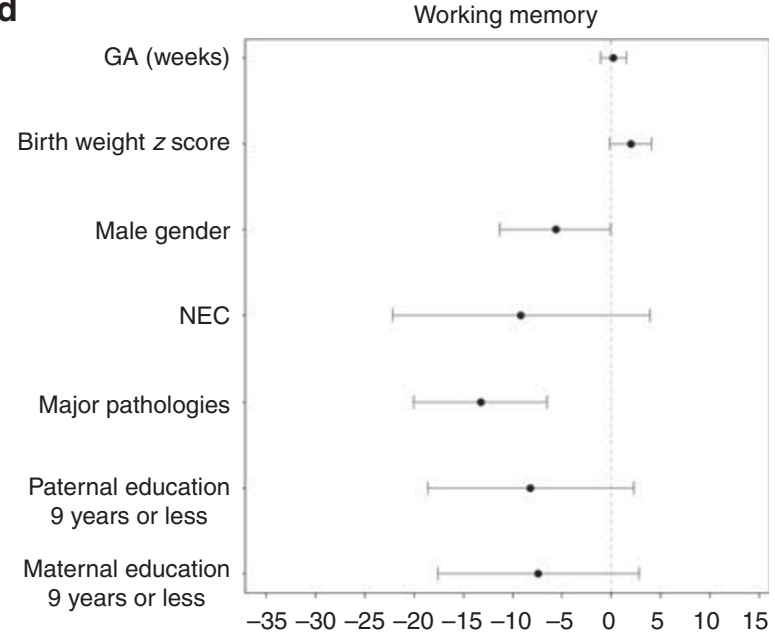

Figure 3. Regression coefficients and $95 \%$ confidence intervals for risk factors of full-scale IQ and four domains (verbal comprehension, perceptual reasoning, working memory, processing speed) of WISC-IV.

extremely preterm in 1997. In that study $(n=189)$, the mean full-scale IQ was 93.1, and $11 \%$ of the children had a full-scale IQ below 70. In the present study, the mean full-scale IQ of the very preterm children was 87.7 (10\% had a full-scale IQ below 70), and in the subgroup of children born extremely preterm, the mean full-scale IQ was 85.1 ( $13 \%$ had a full-scale IQ below 70). Compared with the Australian cohort, the children in the present study born in 2000s were 3 years older 


\section{Articles | Nyman et al.}

at the time of cognitive assessment. In summary, based on the WISC-IV $(10,11)$ results, weaker cognitive performance is still in 2000s evident in a very preterm population at later school age.

In line with previous studies $(2,15,16)$, the children born very preterm in this study also performed significantly below the normative data in all four WISC-IV $(10,11)$ domains (i.e., verbal comprehension, perceptual reasoning, working memory, and processing speed) even when the children with NSI were excluded. Comparing with the previous literature concerning specific neuropsychological deficits of children born preterm (4), surprisingly, impairments in perceptual reasoning and working memory were not evident in the WISC-IV profile. One explanation might be that WISC-IV $(10,11)$ highlights more fluid reasoning in perceptual reasoning than previous versions. According to our results, specific neuropsychological tests are needed to find out the specific visuospatial deficits of children born preterm. Further, children born preterm are reported to have deficits especially in visuospatial working memory (29). Working memory tests of WISC-IV are mainly verbal and may not bring up the specific working memory deficits of children born preterm. However, the four separate domains of cognitive performance were found to be valuable in identifying the role of different risk factors for later cognitive development. The only significant risk factor for full-scale IQ was major brain MRI pathologies. When considering all four domains of WISC-IV $(10,11)$, we could demonstrate that low paternal education, male gender, and birth weight $z$ score were also risk factors for different aspects of cognition.

The prognostic value of neonatal brain injury for later general cognitive development has been controversial in the literature (5). Differences in inclusion and exclusion criteria may partly explain the contradictions, as some studies have excluded cognitively impaired children, untestable children, or children with NSI. In the PIPARI Study cohort, the brain MRI findings at term age have been shown to be associated with cognitive development at 2 and 5 years of age $(18,24)$, and good stability of cognitive development was shown between 2 and 5 years of age (19). In this study, good correlation was shown between 5 and 11 years of age in the cognitive outcome of children born very preterm. This study including children with cognitive and/or NSIs, having a major brain MRI pathology, was the most important risk factor for the weaker cognitive performance associated with full-scale IQ (a 15-point deficit) and with all four domains.

At the age of 5 years, children born very preterm had a 9point difference to the PIPARI study controls whose outcome we have previously reported (19). At the age of 11 years, a 13point difference was found between the children born preterm and the updated mean WISC-IV norms $(10,11)$. Our results suggest good stability of cognitive impairment between the ages of 5 and 11 years. Further, our results suggest that cognitive assessments before school entry are reliable to anticipate later development and are clinically valuable to identify those children who need developmental support.
The domains of verbal comprehension and perceptual reasoning from the WISC-IV $(10,11)$ both set high demands on different aspects of fluid reasoning. This study did not find any specific risk factors that were associated only with perceptual reasoning, although the effect of major pathologies in brain MRI remained even when children with NSI were excluded. In the present study, the specific impact of lower paternal education on lower verbal comprehension became evident (a 15-point deficit). The association between maternal education and verbal comprehension was in the same direction as by fathers but statistically nonsignificant. Although the influence of parental education on cognitive and especially verbal development is described in both fullterm and preterm populations (30-33), the independent effect of paternal education is less well studied. There are several mechanisms potentially explaining the specific role of father on the language development of their children, including genetic factors and a developmentally supportive growth environment. In a recent study, father's social and working status are found to predict the child's lexical development (34). Previous results have also suggested that fathers use more questions and require clarification when talking with their young children (35). Further, diversity and quantity of vocabulary inputs are important factors for children's language acquisition (36).

WISC-IV $(10,11)$ highlights the role of working memory and processing speed in general cognition more than previous versions. These two domains require good attentional skills (10), which are especially vulnerable in children born preterm $(4,37)$. Gender differences were found in our cohort, only in working memory and processing speed. Mortality, neonatal complications, and developmental delay are more common in boys born preterm than in girls. The gender difference in cognitive development is suggested to diminish with age (5). In the present study, however, male gender continued to be a risk factor for working memory and processing speed functions up to later school age. Birth weight $z$ score, which reflects antenatal growth, specifically impaired processing speed. In the present study cohort at the age of 5 years, poor antenatal growth was associated with a more immature white matter structure at term age (38). Our results suggest that immature white matter at term age may have association to the cognitive development of children born very preterm still at 11 years of age.

The strength of this long-term follow-up study is its high follow-up rate. Moreover, all of the assessments were conducted by an experienced neuropsychologist using the full cognitive assessment instead of abbreviated measures. Data concerning perinatal and neonatal risk factors were also systematically collected. Our results revealed potential protective factors for long-term cognitive development of children born very preterm. Higher parental, especially paternal, education is a protective factor. In addition, absence of major pathologies was associated with better cognitive outcome. In this study, girls had better working memory and processing speed skills than boys had. However, relying only 


\section{Cognitive profile of preterm children 1 Articles}

on test norms instead of having a control group of full-term born children may attenuate the severity of cognitive impairments. The Finnish standardization of the WISC-IV $(10,11)$ was published when the data collection started, and the norms were up to date. A possible technical limitation is the MRI equipment used in the first part of the cohort, as more advanced and accurate imaging techniques can detect white matter lesions in more detail. There are also other neonatal and concurrent factors not considered in this study that may also have an impact on cognitive outcomes at school age (e.g., parenting stress and family structure) (39). The children lost to follow-up were significantly more likely to have severe retinopathy of prematurity and have mothers with fewer years of education, which may have biased the cognitive results to a more positive direction.

In conclusion, this study showed that less than one-third of the children born very preterm had clinically significant cognitive difficulties at 11 years of age. Major brain pathologies at term age were associated with poorer general cognitive performance. Paternal education, gender, and birth weight $z$ score emerged as factors affecting different aspects of the cognitive profile.

\section{SUPPLEMENTARY MATERIAL}

Supplementary material is linked to the online version of the paper at http://www.nature.com/pr

\section{ACKNOWLEDGMENTS}

All phases of this study were supported by a grant from the C.G. Sundell Foundation.

\section{MEMBERS OF THE PIPARI STUDY GROUP}

Karoliina Aho; Annarilla Ahtola; Mikael Ekblad; Satu Ekblad; Eeva Ekholm; Leena Haataja; Camilla Hagelstam; Mira Huhtala; Maija Juntunen; Pentti Kero; Mari Koivisto; Riikka Korja; Satu Korpela; Katri Lahti; Helena Lapinleimu; Liisa Lehtonen; Tuomo Lehtonen; Marika Leppänen; Annika Lind; Hanna Manninen; Jaakko Matomäki; Jonna Maunu; Petriina Munck; Laura Määttänen; Pekka Niemi; Anna Nyman; Pertti Palo; Riitta Parkkola; Liisi Rautava; Päivi Rautava; Katriina Saarinen, Physiotherapist; Susanna Salomäki; Virva Saunavaara; Sirkku Setänen; Matti Sillanpää; Suvi Stolt; Päivi Tuomikoski-Koiranen; Timo Tuovinen; Anniina Väliaho; Milla Ylijoki.

Disclosure: The authors declare no conflict of interest.

\section{REFERENCES}

1. Aarnoudse-Moens CSH, Weisglas Kuperus N, van Goudoever J, Oosterlaan J. Meta-analysis of neurobehavioral outcomes in very preterm and/or very low birth weight children. Pediatrics 2009;124:717-28.

2. Hutchinson EA, De Luca CR, Doyle LW, Roberts G, Anderson PJVictorian Infant Collaborative Study Group. School-age outcomes of extremely preterm or extremely low birth weight children. Pediatrics 2013;131:e1053-61.

3. Kerr Wilson CO, Mackay DF, Smith GCS, Pell JP. Meta-analysis of the association between preterm delivery and intelligence. J Public Health 2012;34:209-16.

4. Anderson P. Neuropsychological outcomes of children born very preterm. Semin Fetal Neonatal Med 2014;19:90-6.

5. Linsell L, Malouf R, Morris J, Kurinczuk JJ, Marlow N. Prognostic factors for poor cognitive development in children born very preterm or with very low birth weight: a systematic review. JAMA Pediatr 2015;:1-11.
6. Adams Chapman I, Hansen N, Stoll B, Higgins R. Neurodevelopmental outcome of extremely low birth weight infants with posthemorrhagic hydrocephalus requiring shunt insertion. Pediatrics 2008;121:e1167-77.

7. Marret S, Marchand Martin L, Picaud J, et al. Brain injury in very preterm children and neurosensory and cognitive disabilities during childhood: the EPIPAGE cohort study. PLoS ONE 2013;8:e62683.

8. Woodward L, Clark CAC, Bora S, Inder T. Neonatal white matter abnormalities an important predictor of neurocognitive outcome for very preterm children. PLoS ONE 2012;7:e51879.

9. Sherlock RL, Anderson PJ, Doyle LW. Neurodevelopmental sequelae of intraventricular haemorrhage at 8 years of age in a regional cohort of ELBW/very preterm infants. Early Hum Dev 2005;81:909-16.

10. Wechsler D. Wechsler Intelligence Scale for Children -IV. Käsikirja II. Teoriatausta, standardointi ja tulkinta (Handbook II. Theoretical background, standardization and interpretation). Jyväskylä Psykologien Kustannus 2011.

11. Wechsler D. Wechsler Intelligence Scale for Children -IV. Käsikirja I. Esitys ja -pisteytysohjeet (Handbook I. Administration and scoring). Jyväskylä Psykologien Kustannus 2011.

12. Herber Jonat S, Streiftau S, Knauss E, et al. Long-term outcome at age 7-10 years after extreme prematurity - a prospective, two centre cohort study of children born before 25 completed weeks of gestation (19992003). J Matern Fetal Neonatal Med 2014;27:1620-6.

13. Vinall J, Miller S, Bjornson B, et al. Invasive procedures in preterm children: brain and cognitive development at school age. Pediatrics 2014;133:412-21.

14. Soria Pastor S, Padilla N, Zubiaurre Elorza L, et al. Decreased regional brain volume and cognitive impairment in preterm children at low risk. Pediatrics 2009;124:e1161-70.

15. McNicholas F, Healy E, White M, et al. Medical, cognitive and academic outcomes of very low birth weight infants at age 10-14 years in Ireland. Ir J Med Sci 2014;183:525-32.

16. Serenius F, Ewald U, Farooqi A, et al. Neurodevelopmental outcomes among extremely preterm infants 6.5 years after active perinatal care in Sweden. JAMA Pediatr 2016;170:954-63.

17. Himmelmann K, Hagberg G, Beckung E, Hagberg B, Uvebrant P. The changing panorama of cerebral palsy in Sweden. IX. Prevalence and origin in the birth-year period 1995-1998. Acta Paediatr 2005;94:287-94.

18. Setänen S, Haataja L, Parkkola R, Lind A, Lehtonen L. Predictive value of neonatal brain MRI on the neurodevelopmental outcome of preterm infants by 5 years of age. Acta Paediatr 2013;102:492-7.

19. Munck P, Niemi P, Lapinleimu H, Lehtonen L, Haataja L. Stability of cognitive outcome from 2 to 5 years of age in very low birth weight children. Pediatrics 2012;129:503-8.

20. Wechsler D. Wechsler Preschool and Primary Scale of Intelligence -Reviced (Finnish translation). Helsinki Psykologien Kustannus 1995.

21. Johnson S, Hennessy E, Smith R, Trikic R, Wolke D, Marlow N. Academic attainment and special educational needs in extremely preterm children at 11 years of age: the EPICure study. Arch Dis Child Fetal Neonatal Ed 2009;94:F283-9.

22. Peacock J, Marston L, Marlow N, Calvert S, Greenough A. Neonatal and infant outcome in boys and girls born very prematurely. Pediatr Res 2012;71:305-10.

23. Johnson S, Wolke D, Hennessy E, Marlow N. Educational outcomes in extremely preterm children: neuropsychological correlates and predictors of attainment. Dev Neuropsychol 2011;36:74-95.

24. Munck P, Haataja L, Maunu J, et al. Cognitive outcome at 2 years of age in Finnish infants with very low birth weight born between 2001 and 2006. Acta Paediatr 2010;99:359-66.

25. Setänen S, Lehtonen L, Parkkola R, Aho K, Haataja L, PIPARI Study Group. Prediction of neuromotor outcome in infants born preterm at 11 years of age using volumetric neonatal magnetic resonance imaging and neurological examinations. Dev MedChild Neurol 2016;58:721-7.

26. Domellöf E, Johansson A, Farooqi A, Domellöf M, Rönnqvist L. Relations among upper-limb movement organization and cognitive function at school age in children born preterm. J Dev Behav Pediatr 2013;34:344-52. 


\section{Articles | Nyman et al.}

27. Conrad A, Richman L, Lindgren S, Nopoulos P. Biological and environmental predictors of behavioral sequelae in children born preterm. Pediatrics 2010;125:e83-9.

28. Roberts G, Anderson P, Doyle L. Neurosensory disabilities at school age in geographic cohorts of extremely low birth weight children born between the $1970 \mathrm{~s}$ and the 1990 s. J Pediatr 2009;154:829 34.eI.

29. Korpela S, Nyman A, Munck P, et al. Working memory in very-lowbirthweight children at the age of 11 years. Child Neuropsychol 2016;1: $1-16$.

30. Ko G, Shah P, Lee S, Asztalos E. Impact of maternal education on cognitive and language scores at 18 to 24 months among extremely preterm neonates. Am J Perinatol 2013;30:723-9.

31. Wong H, Edwards P. Nature or nurture: a systematic review of the effect of socio-economic status on the developmental and cognitive outcomes of children born preterm. Matern Child Health J 2013;17: 1689-700.

32. Beaino G, Khoshnood B, Kaminski M, et al. Predictors of the risk of cognitive deficiency in very preterm infants: the EPIPAGE prospective cohort. Acta Paediatr 2011;100:370-8.
33. Bradley R, Corwyn R. Socioeconomic status and child development. Ann Rev Psychol 2002;53:371-99.

34. Korpilahti P, Kaljonen A, Jansson Verkasalo E. Identification of biological and environmental risk factors for language delay: The Let's Talk STEPS study. Infant Behav Dev 2016;42:27-35.

35. Leech K, Salo V, Rowe M, Cabrera N. Father input and child vocabulary development: the importance of Wh questions and clarification requests. Semin Speech Lang 2013;34:249-59.

36. Rowe M. A longitudinal investigation of the role of quantity and quality of child-directed speech in vocabulary development. Child Dev 2012;83: 1762-74

37. Sucksdorff M, Lehtonen L, Chudal R, et al. Preterm birth and poor fetal growth as risk factors of attention-deficit/ hyperactivity disorder. Pediatrics 2015;136:e599-608.

38. Lepomäki V, Leppänen $M$, Matomäki J, et al. Preterm infants' early growth and brain white matter maturation at term age. Pediatr Radiol 2013;43:1357-64.

39. Huhtala M, Korja R, Lehtonen L, et al. Parental psychological well-being and cognitive development of very low birth weight infants at 2 years. Acta Paediatr 2011;100:1555-60. 